\title{
Electrical and Thermal Conductivity of Cyclic Natural Rubber/Graphene Nanocomposite Prepared by Solution Mixing Technique
}

\author{
Vivi Purwandari ${ }^{1,2}$, Saharman Gea ${ }^{3,}$, Basuki Wirjosentono $^{3}$, Agus Haryono ${ }^{4}$, \\ I Putu Mahendra ${ }^{1}$, and Yasir Arafat Hutapea ${ }^{3}$
}

${ }^{1}$ Postgraduate School, Department of Chemistry, Faculty of Mathematics and Natural Sciences, Universitas Sumatera Utara, Jl. Bioteknologi No. 1, Medan 20155, Indonesia

${ }^{2}$ Department of Chemistry, Universitas Sari Mutiara, Jl. Kapten Muslim, Medan 20124, Indonesia

${ }^{3}$ Department of Chemistry, Faculty of Mathematics and Natural Sciences, Universitas Sumatera Utara, Jl. Bioteknologi No. 1, Medan 20155, Indonesia

${ }^{4}$ Research Center for Chemistry, Indonesian Institute of Sciences, Kawasan PUSPIPTEK, Serpong 15314, South Tangerang, Banten, Indonesia

\section{*Corresponding author:}

tel: $+62-85297978578$

email:s.gea@usu.ac.id

Received: April 4, 2019

Accepted: September 4, 2019

DOI: $10.22146 /$ ijc. 44791

\begin{abstract}
Thermal and electrical conductivity studies of Cyclic Natural Rubber nanocomposite with graphene 1 and 2 phr (G1 and G2), and modified 1 and 2 graphenes ( $m G 1$ and $m G 2$ ) have been carried out. Graphene was activated with cetrimonium bromide (CTAB), was isolated from Sawahlunto coal (Bb) by the Hummer modification method. The nanocomposite was fabricated through the mixing solution method using xylene as a solvent. The characterizations of nanocomposites, which were performed by Fourier Transform Infrared (FT-IR) and X-Ray Diffraction (XRD) reveal an interaction between graphene, CTAB, and the CNR matrix. Furthermore, the results of Scanning Electron Magnetic (SEM) and Transmission Electron Microscopy (TEM) analysis indicate that the particle size becomes smaller, and the particle distribution is more in accordance with CTAB. Thermal analysis of nanocomposites using Differential Scanning Calorimeter (DSC) showed an increase in thermal conductivity from $3.0084 \mathrm{~W} / \mathrm{mK}$ to $3.5569 \mathrm{~W} / \mathrm{mK}$. Analysis of electrical conductivity using the Two-Point Probe shows 2 phr $m G(m G 2)$ capable of increasing electrical conductivity from $0.1170 \times 10^{-4} \mathrm{~S} / \mathrm{cm}$ to $0.2994 \times 10^{-4} \mathrm{~S} / \mathrm{cm}$.
\end{abstract}

Keywords: CNR; graphene; coal; CTAB; electrical conductivity

\section{- INTRODUCTION}

The addition of a small amount of graphene to the polymer matrix was found to increase the electrical conductivity of nanocomposites significantly [1-2]. The electrical conductivity of the nanocomposite can be increased by chemically reducing GO [3-4]. Pure graphene is not compatible with all types of organic polymers, and composites obtained have inhomogeneous morphology.

On the other hand, the surface functionalization of graphene can increase the dispersion of graphene into the polymer matrix and also increase the interaction between phases between graphene and the polymer matrix [5-6].
Graphene functionalization has good solubility in organic solvents and good interface interaction with organic polymers [6]. Another reason for graphene functionality significance is that hydrophobic graphene usually forms irreversible agglomeration and produces graphite through van der Waals bonds. This phenomenon has the effect of reducing the surface area of graphene and reducing the electrical properties of graphene [7].

Kim et al. showed an increase in dispersion between styrene butadiene (SBR) latex and multi-layer graphene/CTAB. Multi-layer graphene is more effective 
and stably dispersed in the SBR matrix by CTAB because of the electrostatic attraction between fillers and negatively charged colloidal SBR particles [7]. Based on this, CTABgraphene functionalization is used to enhance interface interactions in the matrix [8-9].

CNR has weak adhesion properties to polar surfaces [10-11] as a non-electrically conductive material, and it has a great potency to develop CNR as a conductive paint. Many previous studies employed natural rubber nanocomposite as a matrix and graphene or functionalized graphene as a filler [12-14], but for graphene fillers obtained from Sawahlunto coal, it has never been reported before. Cyclic Natural Rubber (CNR) has also never been reported as a matrix with graphene fillers. This study used CNR as an insulator as a matrix and graphene from Sawahlunto coal as a nanofiller. The resulting nanocomposite is expected to be a conductive paint resin.

Therefore, the aim of this research is to prepare and evaluate the electrical and thermal conductivity of $\mathrm{CNR} /$ graphene composite by looking at the effect of the amount of graphene and modification of graphene, which is added as nanofiller.

\section{- EXPERIMENTAL SECTION}

\section{Materials}

Materials used were natural graphite (coal) from Sawahlunto River Parambahan village of Stone Tanjung District of Talawi Cit, Central Sawahlunto, West Sumatra, Indonesia. The Cyclic Natural Rubber (CNR) obtained from PTPN III, Sumatera Utara - Indonesia. Sulfuric acid 98\%, sodium nitrate, potassium permanganate, hydrochloric acid $36 \%$, hydrogen peroxide, CTAB were all of analytical-grade and obtained from Sigma-Aldrich (USA), demineralized water and xylene were purchased from Bratachem, Medan-Indonesia.

\section{Procedure}

\section{Synthesis of graphene oxide and graphene from Sawahlunto coal}

The fine powder of Sawahlunto coal was placed in an oven at $125^{\circ} \mathrm{C}$ for $24 \mathrm{~h}$. The powder was converted into GO by the oxidation process. The amount of $1 \mathrm{~g}$ of graphite Sawahlunto coal (g-Bb) and $50 \mathrm{mg}$ of sodium nitrate was introduced into $70 \mathrm{~mL}$ of sulphuric acid $(98$ wt.\%), the reaction was placed in the ice bath. After that, as many as $3 \mathrm{~g}$ of $\mathrm{KMnO}_{4}$ was added into the solution gradually. The solution was stirred for $2 \mathrm{~h}$, and it was diluted using deionized water. The $30 \%$ of hydrogen peroxide was added into the previous solution until the color was turned into bright yellow. It indicated that the oxidation process of graphite was perfectly done. The mixture was filtrated and washed with dilute $\mathrm{HCl}$ to remove the other mineral. The $\mathrm{pH}$ of the previous solution was neutralized using deionized water. The obtained graphite oxide dispersion was treated using ultrasonication with frequency $50-60 \mathrm{~Hz}$ for $90 \mathrm{~min}$ [7,15-16]. The brown color of water dispersion indicated the presence of a stable Nano sheet's graphene oxide $(\mathrm{GO}-\mathrm{Bb})$. The reduction process of the exfoliation results (GO-Bb900) was performed using the $1 \% \mathrm{NaBH}_{4}$ in $0.2 \% \mathrm{NaOH}$. The mixture was stirred for $1 \mathrm{~h}$, and $6 \mathrm{M}$ $\mathrm{HCl}$ was added drop by drop until the air bubbles were disappeared. After that, the precipitate was formed and then washed with $\mathrm{DM}$ water until the $\mathrm{pH}$ was neutral. The precipitate was then dried at $100^{\circ} \mathrm{C}$ for $12 \mathrm{~h}$. Finally, the graphene powder was successfully manufactured from Sawahlunto coal (G-Bb900). The obtained graphene oxide (GO-Bb) and graphene (G-Bb) were evaluated using XRD, SEM, TEM and FT-IR analysis.

\section{Graphene functionalization and nanocomposite preparation}

Two gram of graphene oxide (GO-Bb) was dispersed in $100 \mathrm{~mL}$ of deionized water that assisted with ultrasonication. On the other side, $2 \mathrm{~g}$ of CTAB was dissolved in $100 \mathrm{~mL}$ of ethanol. Those two solutions were mixed and stirred for $24 \mathrm{~h}$ at room temperature. This treatment was continued with the addition of $10 \mathrm{~mL}$ of $1 \mathrm{wt} . \% \mathrm{NaBH}_{4}$ and $0.2 \mathrm{wt}$.\% $\mathrm{NaOH}$ and stirred for $24 \mathrm{~h}$. The obtained black powder (mG) was washed several times using a mixture of deionized water and ethanol with the ratio $1: 1$, and the powder was dried at $60{ }^{\circ} \mathrm{C}$ until the weight was constant [17-18]. The composite was prepared using solution mixing between CNR and $\mathrm{mG}$. The amount of 1and $2 \mathrm{phr} \mathrm{mG}$ was dispersed in $20 \mathrm{~mL}$ of xylene using ultra-sonication for $1 \mathrm{~h}$. Then, as many as $10 \mathrm{~g}$ of CNR was added into that dispersion and stirred 
until CNR was perfectly dissolved [13]. The solution was cast into an acrylic plate and dried at room temperature for $72 \mathrm{~h}$. The obtained nanocomposites were labeled as $\mathrm{m}$ G1 and $\mathrm{m}-\mathrm{G} 2$ that referred to the addition of 1 and $2 \mathrm{phr}$ of $\mathrm{mG}$.

\section{Characterization}

The FT-IR spectra of the as-prepared GO and nanocomposite were determined using ATR-IR Bruker Alpha Platinum with the wavenumber range between $4000-500 \mathrm{~cm}^{-1}$. The wide-angle X-Ray diffractogram of GO and nanocomposite was evaluate using Shimadzu 7000 with the source of irradiation $\mathrm{Ka} \mathrm{Cu}$. The scan speed was $2^{\circ} / \mathrm{min}$, and the range of $2 \theta$ was $7^{\circ}-70^{\circ}$. The morphology and microstructure of $\mathrm{GO}$ and nanocomposite were determined using SEM JEOL 6510(LA), accelerating voltage of $20.00 \mathrm{kV}$, magnification $\times 2,500$ and TEM JEM1400 , accelerating voltage of 120 Volt, magnification 150,000 , while the thermal conductivity was measured using DSC-60, flow rate $30 \mathrm{~mL} / \mathrm{min}$, scanning from 25 to $600^{\circ} \mathrm{C}$ at the rate $15^{\circ} \mathrm{C} / \mathrm{min}$. The measurement of GO and nanocomposite's electrical resistivity was conducted using a two-point probe.

\section{- RESULTS AND DISCUSSION}

\section{The Characterization of GO}

Fig. 1(a) shows the diffractogram of graphite of (g$\mathrm{Bb})$, graphene oxide (GO-Bb), and graphene (G-Bb)

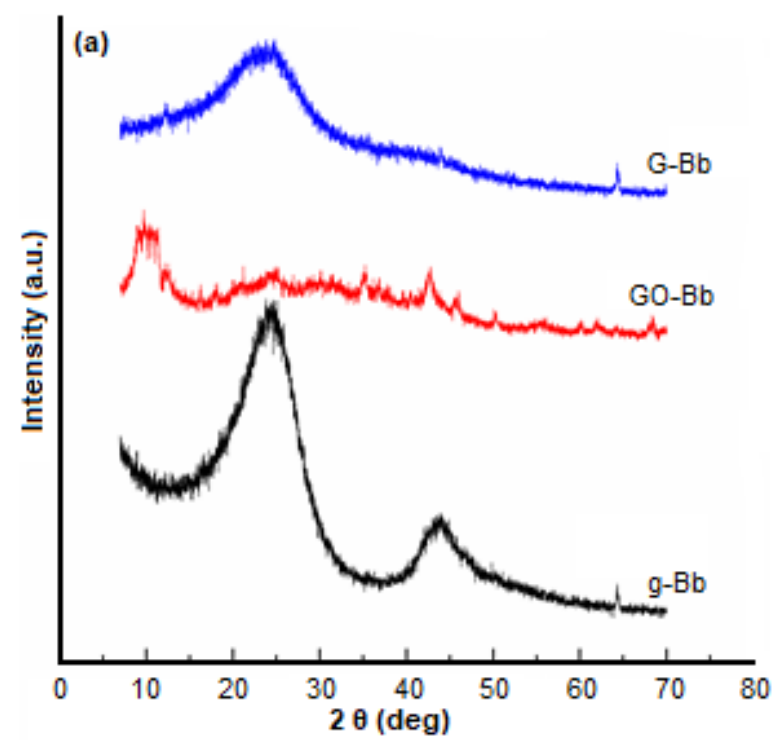

Fig 1. (a) Crystallographic of g-Bb, GO-Bb, G-Bb (b) Crystallographic of CNR, G1/CNR, and mG1/CNR obtained from Sawahlunto coal. For the graphite, it shows a peak at $2 \theta$ of $24.58^{\circ}$ with $d$-spacing $0.1776 \mathrm{~nm}$. The graphene oxide shows a peak at different $2 \theta$, around $11.08^{\circ}$, with the value of $d$-spacing of $0.4008 \mathrm{~nm}$ [18]. The shifting of a peak to the lower value of $2 \theta$ and the increase of the $d$-spacing value were caused by the presence of some functional group in graphene oxide, i.e., epoxy and carbonyl. The reduction process of graphene oxide was conducted using $1 \mathrm{wt} . \% \mathrm{NaBH}_{4}$; as a result, the signal is shifting to $24.0^{\circ}$ of $2 \theta$. This value of $2 \theta$ indicated that the graphene had been successfully obtained by the reduction process of graphene oxide. The increase of $2 \theta$ value in graphene also gives an impact on the decrease of $d$ spacing value to be $0.1894 \mathrm{~nm}$ due to the disappeared of epoxy and carbonyl group in graphene [19-21].

The FT-IR spectra of graphene oxide and graphene can be seen in Fig. 2(a). The particular peak of graphene oxide can be found at 3354,2086, 1621, 1163 and 1040 $\mathrm{cm}^{-1}$. The peak at $3354 \mathrm{~cm}^{-1}$ indicated the presence of hydroxyl group or van der Waals interaction between water and graphene oxide. The second peak at $2086 \mathrm{~cm}^{-1}$ confirmed the presence of vibration of $\mathrm{C}=\mathrm{O}$ stretching from aldehyde, ketone, and ester. The $\mathrm{C}=\mathrm{C}$ bonding of aromatic and aliphatic also can be found at $1621 \mathrm{~cm}^{-1}$. The last peak was found in 1163 and $1040 \mathrm{~cm}^{-1}$, which indicated the presence of $\mathrm{C}-\mathrm{O}-\mathrm{C}$ and $\mathrm{C}=\mathrm{C}-\mathrm{H}$ or $\mathrm{Ar}-\mathrm{H}$ [22-24].

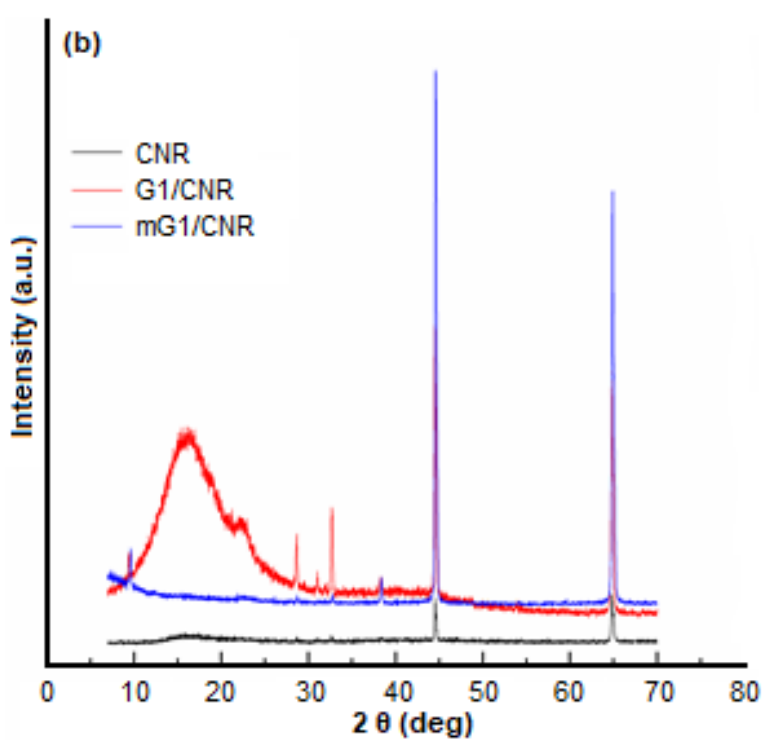



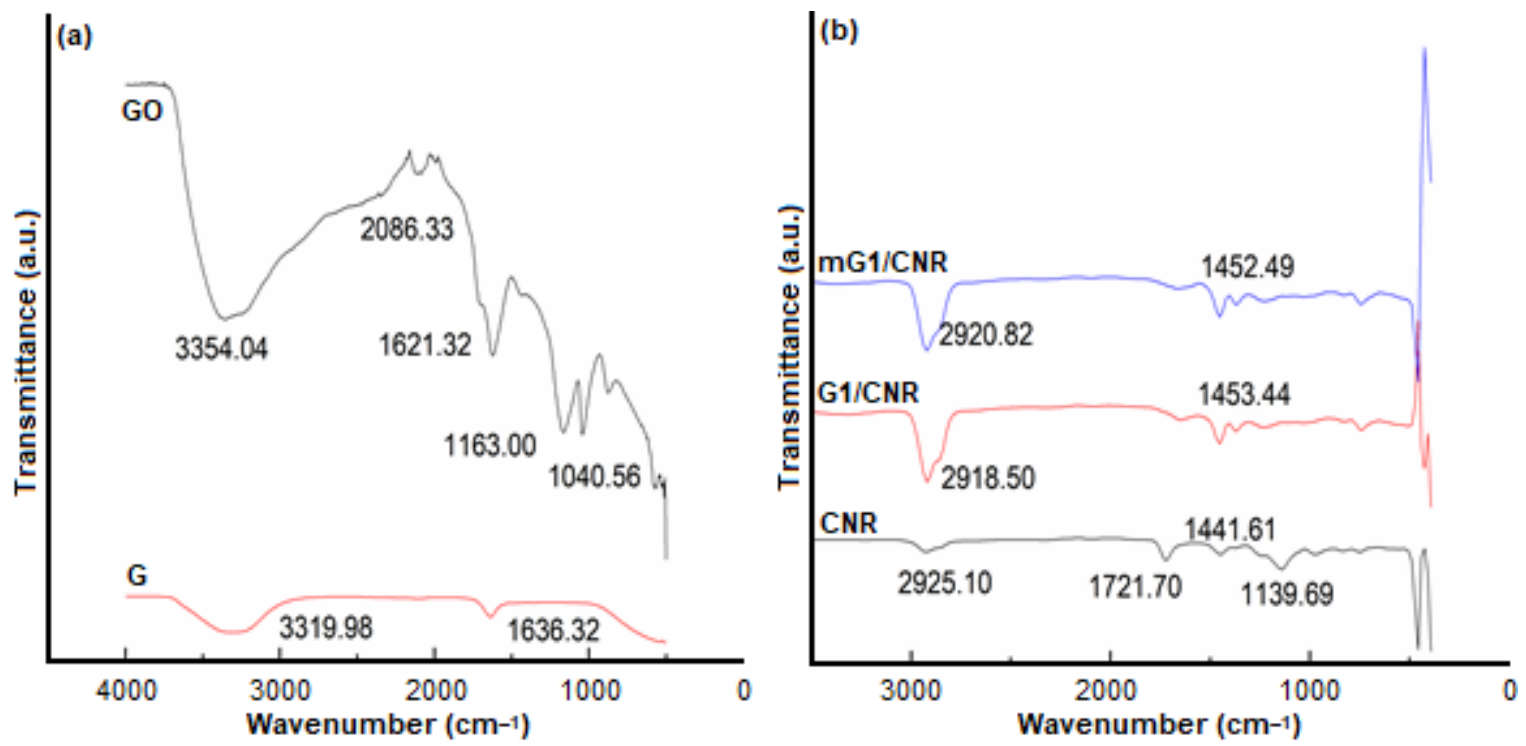

Fig 2. (a) FTIR spectra of GO-Bb and G-Bb, (b) FTIR spectra of CNR, G1/CNR, and mG1/CNR

Kumar et al. (2014) have already synthesized graphene from bituminous. The FT-IR of the reduced graphene oxide showed the functional group that contains oxygen almost disappeared. The particular peak of graphene in this research showed a similarity with the previous work, and it appears at $1600 \mathrm{~cm}^{-1}$ that refers to the skeleton of graphite that was not perfectly oxidized [18].

Fig. 1 (b) showed the crystallographic of G1 and mG1 that dispersed in the CNR matrix. There is a shifting signal at $2 \theta$ of $24^{\circ}$ and $14^{\circ}$ that is caused by the graphene's intercalating in the non-polar matrix of CNR. In the nanocomposite $\mathrm{mG} / \mathrm{CNR}$, there is no particular signal of $\mathrm{mG}$; it is dominated by the signal of material, which has a long carbon structure [25], i.e., CNR, but the presence of CNR increase the crystallinity of nanocomposite [26]. The other characteristic of nanocomposite was identified using FT-IR to show the functional group that presence in the material. Fig. 2(b) shows the FT-IR spectra of CNR, G1/CNR, and mG1/CNR; those spectra have a similar peak at $2920-2925 \mathrm{~cm}^{-1}$ and $1441-1452 \mathrm{~cm}^{-1}$ that indicated the presence of vibration of $\mathrm{C}-\mathrm{H}$ stretching and $\mathrm{C}-\mathrm{H}$ bending. The disappeared of the peak at 1139, and 1721 was interpreted as the formation of $\mathrm{C}-\mathrm{H}$ and $\mathrm{C}=\mathrm{C}$ that obtain from the interaction between graphene and CTAB [27].

Graphene modification was conducted reacting graphene oxide with $\mathrm{CTAB}$, which was then reduced using $\mathrm{NaBH}_{4}$. In a graphene peak of $1441 \mathrm{~cm}^{-1}$, it shows
$\mathrm{C}-\mathrm{OH}$ groups originating from unreduced graphene oxide and not bound to CTAB [28]. The spectra of mG1/CNR FTIR also showed almost the same peak, the presence of CTAB was also marked at peak $1453 \mathrm{~cm}^{-1}$ [29]. Similarly, the two peaks of G1/CNR and $\mathrm{mG} 1 / \mathrm{CNR}$ state that graphene modification only occurs on the surface of the graphene plane.

The dispersion of unmodified graphene and modified graphene in a CNR matrix were investigated using SEM and TEM (Fig. 3 and 4). SEM micrographs show that most xylene the matrix area is not filled with graphene filler (Fig. 3(a)) [29]. Modified graphene with $\mathrm{CTAB}$ has a better surface because $\mathrm{mG}$ looks more evenly spread on the CNR matrix.

Fig. 3 shows the nanocomposite microstructure, as shown in the picture, the particle of graphene $(G)$ and modified graphene $(\mathrm{mG})$ in the CNR's matrix has good distribution. Meanwhile, in Fig. 4, the particle of CNR and the nanocomposite is obtained as agglomer. The single particle size in the agglomer of CNR is $25 \mathrm{~nm}$. However, after the addition of graphene or unmodified graphene, the particle size of a single particle of nanocomposite has changed to be $27 \mathrm{~nm}$, and the addition of modified graphene has changed the particle size of a single particle of nanocomposite significantly, to be $6.2 \mathrm{~nm}$. The increase of particle size after the addition of unmodified graphene is due to the incompatibility of 

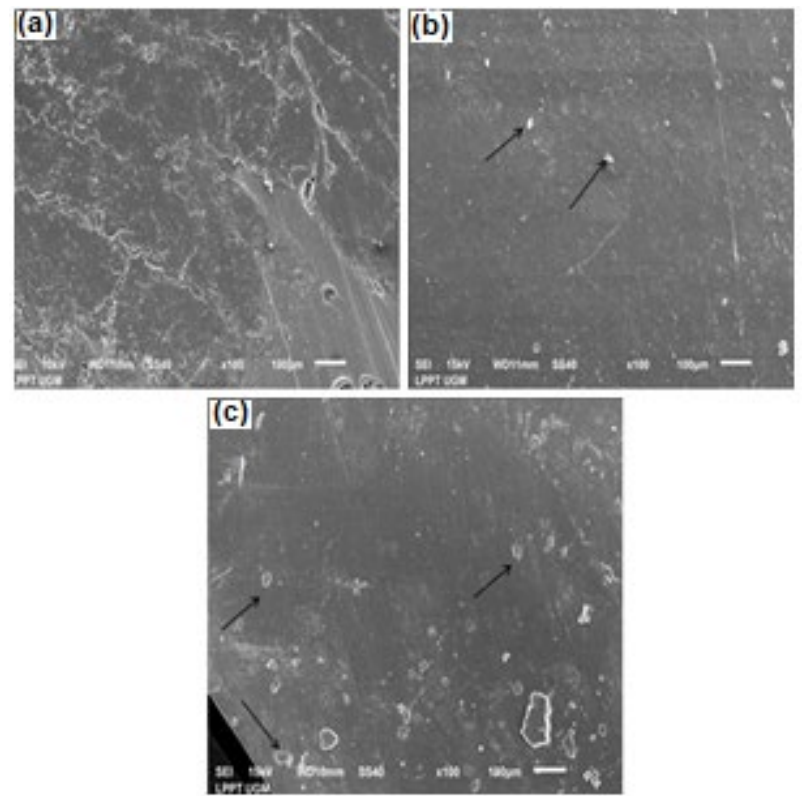

Fig 3. SEM images of (a) CNR, (b) G1/CNR, (c) $\mathrm{mG} 1 / \mathrm{CNR}$

those two materials. The effect of graphene surface modification using $\mathrm{CTAB}$ has a big impact on the enhancement of compatibility between graphene and CNR, evidenced by a significant change in the decrease in nanocomposite and graphene particle size well bound to the CNR matrix [3-4,27,29].

\section{The Thermal and Electrical Conductivity of the Nanocomposite}

\section{Thermal conductivity}

The differential scanning calorimetry has been used to measure the thermal property of nanocomposite. Based on the literature, graphene has good thermal conductivity; it was about $\sim 5000 \mathrm{~W} / \mathrm{mK}$ and has been utilized as a nanofiller in the polymer matrix to enhance the thermal conductivity property. Also, in the previous research graphene has been combined with natural rubber with a good thermal conductivity property [29].

Thermal DSC becomes one technique used to measure the thermal conductivity of solid material by measuring the curve slope. The equation below can be used to determine the thermal conductivity:

Slope $=\frac{\mathrm{d} \Delta \mathrm{P}}{\Delta \mathrm{T}_{\mathrm{p}}}=\frac{2}{\mathrm{R}}$
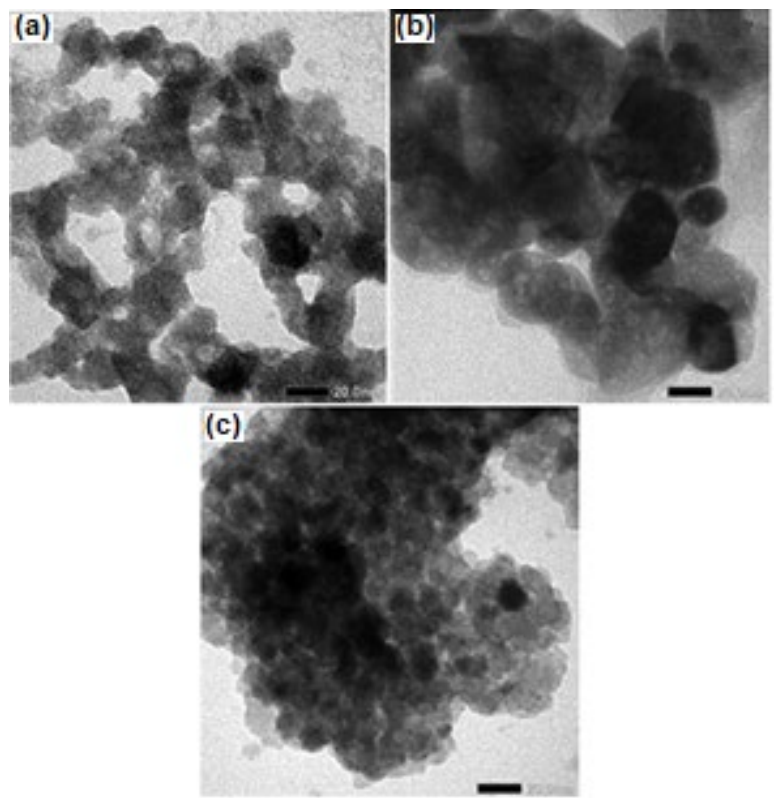

Fig 4. The TEM images of (a) CNR, (b) G1/CNR, (c) $\mathrm{mG} 1 / \mathrm{CNR}$ with the 150,000 magnification

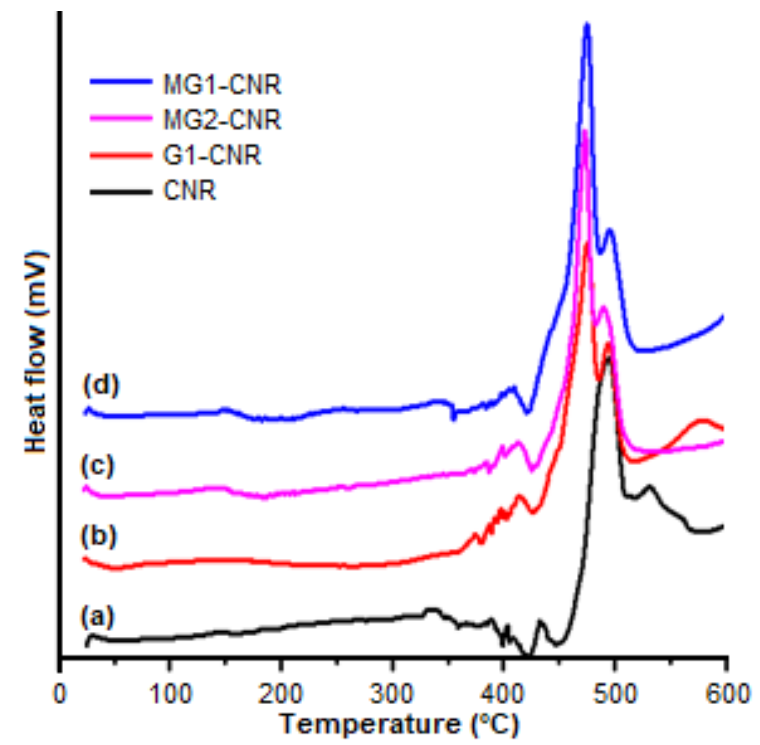

Fig 5. DSC and regression curve of (a) CNR, (b) G1/CNR, (c) mG1/CNR, (d) mG2/CNR

where $\Delta \mathrm{P}$ is the differential value of heat flow after subtracted with the baseline, $\mathrm{T}_{\mathrm{P}}$ is the temperature of DSC during measurement, and $\mathrm{R}$ is the total of resistance [30-31]. The thermal DSC and regression curve along with thermal conductivity of CNR matrix after the addition of unmodified and modified graphene can be seen in Fig. 5 and Fig. 6, respectively. 


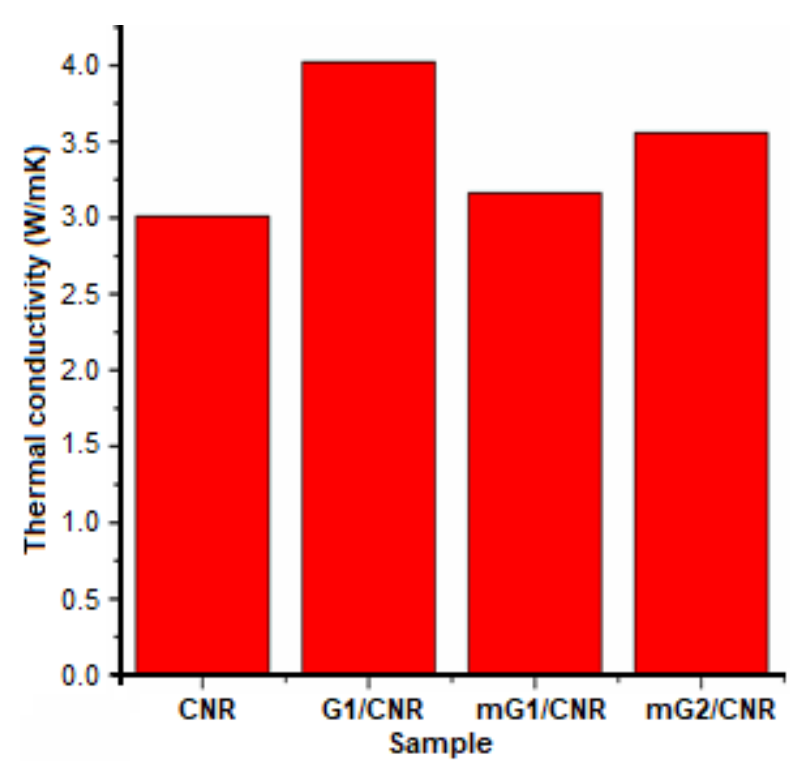

Fig 6. Thermal conductivity of CNR and nanocomposite measured by DSC

After the addition of unmodified graphene, the thermal conductivity value increased to $4.0203 \mathrm{~W} / \mathrm{mK}$, but after the addition of $1 \mathrm{phr}$ of modified graphene, the value decreased to $3.1635 \mathrm{~W} / \mathrm{mK}$ and observed an increase in being after the addition of $2 \mathrm{phr}$ modified graphene. This decrease in thermal conductivity of graphene modification $1 \mathrm{phr}$ (mG1/KAS) is due to the non-polar long alkyl group on CTAB [32].

The addition of unmodified graphene to the $\mathrm{CNR}$ matrix reduced the CNR Tg from 96.21 to $95.02^{\circ} \mathrm{C}$. Also, there was a slight decrease in $\mathrm{Tg}$ with modified graphene from 96.21 to $92.83^{\circ} \mathrm{C}$ and $94.21^{\circ} \mathrm{C}$ for $1 \mathrm{phr}$ and $2 \mathrm{phr}$ of $\mathrm{mG}$. Furthermore, the Tg showed that modified graphene did not show a significant effect on changes in matrix Tg. However, the modified graphene $\mathrm{Tg}$ was much lower than the unmodified graphene. This is due to the fact that modified graphene is more integrated into the CNR matrix than unmodified graphene [31-32].

\section{Electrical conductivity}

The electrical conductivity is the ability of a material to conduct electricity. Graphene, with its electrical conductivity, is able to change the polymer property from an insulator to be a conductive material [29]. Fig. 7 shows the change of electrical conductivity after the addition of unmodified and modified graphene in the NR matrix, which is an insulator.

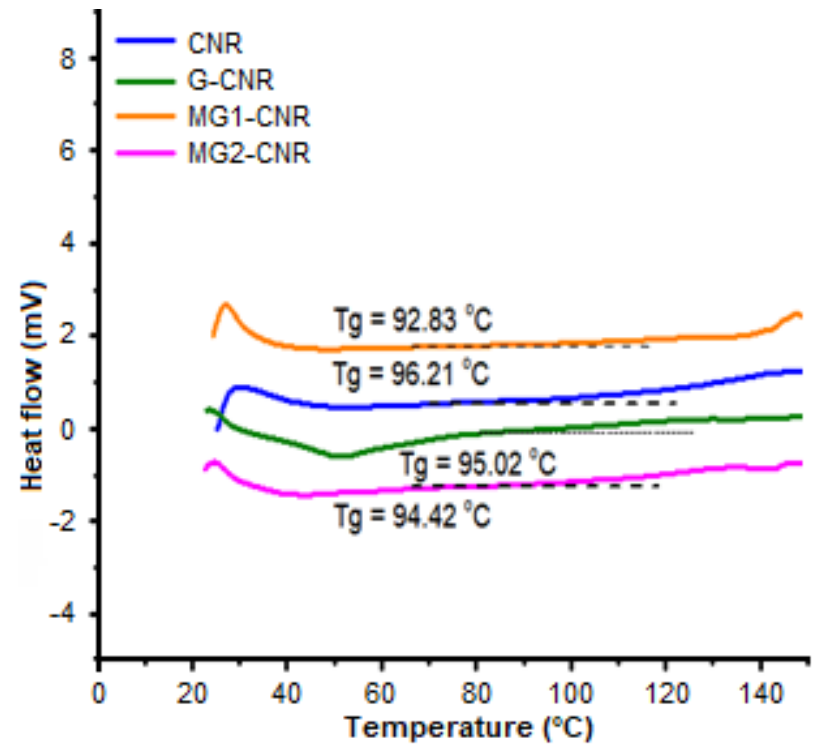

Fig 7. Glass transition temperature ( $\mathrm{Tg}$ ) of Nanocomposite

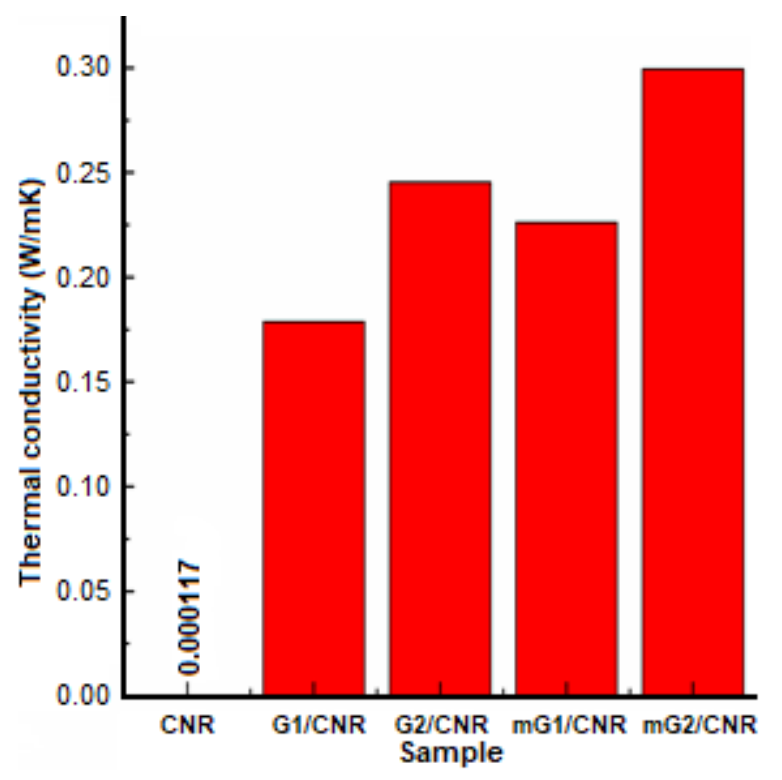

Fig 8. The result characterization of $G / C N R$ and mG/CNR nanocomposite using Two-Point Probe method

Based on Fig. 8, the addition of 1 and 2 phr of unmodified graphene into the CNR matrix contribute to an increase in the thermal conductivity of CNR to be 0.1781 and $0.2453 \times 10^{-6} \mathrm{~S} / \mathrm{cm}$. After the addition of modified graphene with the same concentration, it gave a value of 0.2262 and $0.2994 \times 10^{-6} \mathrm{~S} / \mathrm{cm}$. Based on this value, unmodified and modified graphene changes the electrical property of CNR from an insulator to be 
semiconductor [29]. This trend shows that the increase in electrical conductivity is depending on the concentration of unmodified and modified graphene. The low value of this electrical conductivity was caused by the presence of the agglomeration process between $\mathrm{CNR}$ and the unmodified and modified graphene (Based on TEM result) [33-34].

\section{- CONCLUSION}

The fabrication of nanocomposites with Cyclic Natural Rubber (CNR) as a matrix, and graphene oxide (isolated from Sawahlunto coal) mixed with cetrimonium bromide (CTAB) cationic surfactant, which was then reduced with $\mathrm{NaBH}_{4}$ with the solution mixing method was conducted and was proven to be able to increase the $\mathrm{CNR} /$ graphene nanocomposite functionalization. The nanocomposite electrical conductivity was measured by using the Two-point probe. The resulted non-polar CNR matrix with the addition of unmodified graphene filler and modified graphene was able to increase the electrical conductivity into semiconductor nanocomposite. By using Differential Scanning Calorimeter (DSC), it shows an increase in thermal conductivity with the addition of unmodified graphene and modified graphene from CNR.

\section{- ACKNOWLEDGMENTS}

Authors would like to acknowledge KEMENRISTEK-DIKTI for financial support through Penelitian Disertasi Doktor grant scheme with the contract number of 033/K1.1/LT.1/2018.

\section{- REFERENCES}

[1] Chen, C., Yang, Q.H., Yang, Y., Lv, W., Wen, Y., Hou, P.X., Wang, M., and Cheng, H.M., 2009, Selfassembled free-standing graphite oxide membrane, Adv. Mater., 21 (29), 3007-3011.

[2] Yang, Y.J., and Li, W., 2014, CTAB functionalized graphene oxide/multiwalled carbon nanotube composite modified electrode for the simultaneous determination of ascorbic acid, dopamine, uric acid and nitrite, Biosens. Bioelectron., 56, 300-306.

[3] Phiri, J., Johansson, L.S., Gane, P., and Maloney T., 2018, A comparative study of mechanical, thermal and electrical properties of graphene-, graphene oxide- and reduced graphene oxide-doped microfibrillated cellulose nanocomposites, Composites Part B, 147, 104-113.

[4] Wu, J., Huang, G., Li, H., Wu, S., Liu, Y., and Zheng, J., 2013, Enhanced mechanical and gas barrier properties of rubber nanocomposites with surface functionalized graphene oxide at low content, Polymer, 54 (7), 1930-1937.

[5] Wu, X., Lin, T.F., Tang, Z.H., Guo, B.C., and Huang, G.S., 2015, Natural rubber/graphene oxide composites: Effect of sheet size on mechanical properties and strain-induced crystallization behavior, eXPRESS Polym. Lett., 9 (8), 672-685.

[6] Krishnamoorthy, K., Veerapandian, M., Yun, K., and Kim, S.J., 2013, The chemical and structural analysis of graphene oxide with different degrees of oxidation, Carbon, 53, 38-49.

[7] Fauziyah, N., Sriatun, and Pardoyo, 2015, Adsorption of indigo carmine dye using cetyltrimethylammonium bromide (CTAB) surfactant modified zeolite, JSM, 23 (4), 121-126.

[8] Kang, H., Zuo, K., Wang, Z., Zhang, L., Liu, L., and Guo, B., 2014, Using a green method to develop graphene oxide/elastomers nanocomposites with combination of high barrier and mechanical performance, Compos. Sci. Technol., 92, 1-8.

[9] Zhang, H.B., Zheng, W.G., Yan, Q., Yang, Y., Wang, J.W., Lu, Z.H., Ji, G.Y., and Yu, Z.Z., 2010, Electrically conductive polyethylene terephthalate/ graphene nanocomposites prepared by melt compounding, Polymer, 51 (5), 1191-1196.

[10] Siregar, A.M., Eddiyanto, Wirjosentono, B., and Siregar, A.Z., 2016, Oxidation degradation study and use of phenol and amina antioxidant compounds in natural rubber cyclical, Intl. J. Sci. Technol. Res., 5 (5), 297-299.

[11] Siregar, M.S., Thamrin, Wirjosentono, B., Eddiyanto, and Mendez, J.A., 2014, Grafting of maleic anhydride onto cyclized natural rubber by reactive processing: The effect of maleic anhydride concentrations, Chem. Mater. Res., 6 (11), 15-21.

[12] Liu, H., Li, Y., Dai, K., Zheng, G., Liu, C., Shen, C., Yan, X., Guo, J., and Guo, Z., 2015, Electrically 
conductive thermoplastic elastomer nanocomposites at ultralow graphene loading levels for strain sensor applications, J. Mater. Chem. C, 4 (1), 157-166.

[13] Zhan, Y., Wu, J., Xia, H., Yan, N., Fei, G., and Yuan, G., 2011, Dispersion and exfoliation of graphene in rubber by an ultrasonically-assisted latex mixing and in situ reduction process, Macromol. Mater. Eng., 296 (7), 590-602.

[14] Powell, C., and Beall, G.W., 2015, Graphene oxide and graphene from low grade coal: Synthesis, characterization and applications, Curr. Opin. Colloid Interface Sci., 20 (5-6), 362-366.

[15] Purwandari, V., Gea, S., Wirjosentono, B., and Haryono, A., 2018, Synthesis of graphene oxide from the Sawahlunto-Sijunjung coal via modified hummers method, AIP Conf. Proc., 2049, 020065.

[16] Araby, S., Meng, Q., Zhang, L., Kang, H., Majewski, P., Tang, Y., and Ma, J., 2014, Electrically and thermally conductive elastomer/graphene nanocomposites by solution mixing, Polymer, 55 (1), 201-210.

[17] Bian, J., Wei, X.W., Lin, H.L., Gong, S.J., Zhang, H., and Guan, Z.P., 2011, Preparation and characterization of modified graphite oxide/poly(propylene carbonate) composites by solution intercalation, Polym. Degrad. Stab., 96 (10), 1833-1840.

[18] Kumar, E.S., Sivasankar, V., Sureshbabu, R., Raghu, S., and Kalaivani, R.A., 2017, Facile synthesis of few layer graphene from bituminous coal and its application towards electrochemical sensing of caffeine, Adv. Mater. Lett., 8 (3), 239-245.

[19] Li, G., Yuan, J.B., Zhang, Y.H., Zhang, N., and Liew, K.M., 2018, Microstructure and mechanical performance of graphene reinforced cementitious composites, Composites Part A, 114, 188-195.

[20] Sandhya, P.K., Jose, J., Sreekala, M.S., Padmanabhan, M., Kalarikkal, N., and Thomas, S., 2018, Reduced graphene oxide and $\mathrm{ZnO}$ decorated graphene for biomedical applications, Ceram. Int., 44 (13), 1509215098.

[21] Gea, S., Sari, J.N., Bulan, R., Piliang, A., Amaturrahim, S.A., and Hutapea, Y.A., 2018, Chitosan/graphene oxide biocomposite film from pencil rod, J. Phys. Conf. Ser., 970 (1), 012006.
[22] Stobinski, L., Lesiak, B., Malolepszy, A., Mazurkiewicz, M., Mierzwa, B., Zemek, J., Jiricek, P., and Bieloshapka, I., 2014, Graphene oxide and reduced graphene oxide studied by the XRD, TEM and electron spectroscopy methods, J. Electron. Spectrosc. Relat. Phenom., 195, 145-154.

[23] Tang, Z., Liu, X., Hu, Y., Zhang, X., and Guo, B., 2017, A slurry compounding route to disperse graphene oxide in rubber, Mater. Lett., 191, 93-96.

[24] Gea, S., Barus, D.A., Sibarani, Y.S., Panindia, N., Sari, J.N., Sebayang, K., Ginting, H., and Hutapea, Y.A., 2018, The study on physical and mechanical properties of latex/graphene oxide composite film, J. Phys. Conf. Ser., 1120 (1), 012052.

[25] Lee, J.Y., Kumar, V., Tang, X.W., and Lee, D.J., 2017, Mechanical and electrical behavior of rubber nanocomposites under static and cyclic strain, Compos. Sci. Technol., 142, 1-9.

[26] Matos, C.F., Galembeck, F., and Zarbin, A.J.G., 2014, Multifunctional and environmentally friendly nanocomposites between natural rubber and graphene or graphene oxide, Carbon, 78, 469-479.

[27] Kuila, T., Bose, S., Mishra, A.K., Khanra, P., Kim, N.H., and Lee, J.H., 2012, Chemical functionalization of graphene and its applications, Prog. Mater Sci., 57 (7), 1061-1105.

[28] Camargo, P.H.C., Satyanarayana, K.G., and Wypych, F., 2009, Nanocomposites: Synthesis, structure, properties and new application opportunities, Mater. Res., 12 (1), 1-39.

[29] Park, W., Hu, J., Jauregui, L.A., Ruan, X., and Chen, Y.P., 2014, Electrical and thermal conductivities of reduced graphene oxide/polystyrene composites, Appl. Phys. Lett., 104 (11), 113101.

[30] Camirand, C.P., 2004, Measurement of thermal conductivity by differential scanning calorimetry, Thermochim. Acta, 417 (1), 1-4.

[31] Mu, Q., and Feng, S., 2007, Thermal conductivity of graphite/silicone rubber prepared by solution intercalation, Thermochim. Acta, 462 (1-2), 70-75.

[32] Shiu, S.C., and Tsai, J.L., 2014, Characterizing thermal and mechanical properties of graphene/epoxy nanocomposites, Composites Part B, 
56, 691-697.

[33] Kuilla, T., Bhadra, S., Yao, D., Kim, N.H., Bose, S., and Lee, J.H., 2010, Recent advances in graphene based polymer composites, Prog. Polym. Sci., 35 (11), 1350-1375.
[34] Imran, S.M., Kim, Y., Shao, G.N., Hussain, M., Choa, Y.H., and Kim, H.T., 2014, Enhancement of electroconductivity of polyaniline/graphene oxide nanocomposites through in situ emulsion polymerization, J. Mater. Sci., 49 (3), 1328-1335. 